\title{
Synchrotron bids seek ways to raise money
}

Paris \& London. Britain's research councils are said to be close to giving their formal approval to a $£ 9$-million (US\$13.5 million) upgrade to the 2-GeV Synchrotron Radiation Source (SRS) at Daresbury in Cheshire.

But the difficulties in securing funds for the upgrade suggest that finding the $£ 100$ million needed to build the SRS's proposed successor will be an uphill struggle. Indeed according to laboratory officials, it may need a novel funding approach, such as borrowing' construction money from the government - or even industry - which is then 'paid off' over the lifetime of the instrument.

Synchrotron radiation is emitted from beams of high-energy electrons or positrons when their path around a circular accelerator is bent by magnets. Modern machines maximize the production of such radiation using 'insertion devices' which force the particles to slalom about the linear part of their trajectory. This results in the intense beams of radiation which are widely used to probe the structure of matter.

\section{IMAGE UNAVAILABLE FOR COPYRIGHT REASONS}

DIAMOND: an expensive sparkle in the eyes of Daresbury's synchrotron planners.
The upgrade to SRS would greatly increase its capacity by adding two such insertion devices. But SRS itself will need to be replaced early next century, when it will have become obsolete. Indeed, the SRS is already outperformed by more modern facilities, such as the Advanced Light Source at Berkeley in the United States, the Electra facility in Trieste, Italy, and the Delta and Bessy II synchrotrons being built by Germany in Dortmund and Berlin.

British researchers already use the 6-GeV European Synchrotron Radiation Facility (ESRF), the world's most powerful synchrotron source, which was opened in Grenoble, France, in 1994. But ESRF, like the planned US Advanced Photon Source (see opposite) produces 'hard X-rays', which are used mainly to probe atomic structure.

Many researchers working on biological and other structures also require sources of 'softer X-rays' and ultraviolet radiation. To meet this need, British scientists are proposing the construction of a 'third generation' 3GeV machine, known as Diamond, at a cost of about $£ 100$ million over five years.

The scientific case for Diamond was strongly endorsed last year by the council of the Central Laboratory of the Research Councils (CLRC). But little progress has been made since then, according to an official at the laboratory.

The delays expose what many feel to be the lack of an adequate financial mechanism for supporting big national science facilities in the United Kingdom, particularly after the reorganization of the research councils in the government's white paper of 1993.
As science budgets are squeezed around the world, funding agencies are facing increasing difficulties in raising the money needed for new, large research facilities. The dilemma is particularly acute where these facilities must compete for support against research programmes. On this and the following two pages, we report on particular aspects of this issue that are being faced in Europe, Australia and the United States.

Following, in particular, the splitting up of the former Science and Engineering Research Council (SERC), no individual council has sufficient funds to pay for such projects alone. Conversely, while the CLCR is now responsible for managing large facilities for its research council 'customers', it has no budget of its own for new facilities.

A further complication is the fact that the general squeeze on 'operating costs' in the UK science budget leaves little room for major investment in new equipment (see page 102), hence the idea of developing a new funding mechanism that allows separate procedures for large capital investments and running costs within the science budget.

At the same time, even if the research councils were to agree to finance Diamond, the approval process may be too slow for a decision to be reached within the next 18 months. This timescale needs to be met, according to Ron Newport, the director of the Daresbury Laboratory, if Diamond is to be built before the existing SRS becomes obsolete early next century.

Meanwhile, France and Switzerland have

\section{Australian astronomers are rebuffed in move to apply for}

Sydney. Prolonged uncertainty among Australian astronomers has ended with news that the new government has decided not to support their bid for Australia to become the first non-European member of the European Southern Observatory (ESO).

Various scientific groups have already protested against the decision, which has shortened the honeymoon period for Peter McGauran, the new minister of science and technology. But McGauran says the proposed ESO subscription fee of $\$ \mathbf{A 3 0}$ million (US\$23.7 million) is too expensive for a government planning cuts in public expenditure of $\$ \mathrm{A8}$ billion over the next two years.

The previous Labor government was first approached by a consortium of university and government astronomers two years ago for funding for ESO membership under the Major National Research Facilities scheme, worth \$A62 million over six years.

Australian astronomers had been invited to apply for partnership in the world's largest optical/infrared telescope (the Very
Large Telescope or VLT) being built at Paranal in Chile, partly to contribute their high level of expertise in optical interferometry. The subscription was to have been spread over several years, and the proposal had gained the unanimous and enthusiastic support of a peer review committee. It was ranked as the top project by government committees last year, which proposed support of $\mathbf{A} \$ 28$ million over six years.

This support was overturned at cabinet level by the Labor government before its release of an Innovation Statement last December (see Nature 378, 653; 1995). But after protests from astronomers, led by Jeremy Mould, Director of the Mt Stromlo and Siding Spring Observatories of the Australian National University, the then Minister for Science, Peter Cook, reversed the decision and announced, during the election campaign, that ESO would be a top priority.

Following Labor's election defeat, Mould says that he put the astronomers' case personally to McGauran on 11 April, including an estimate of "tens of millions of dollars' worth of contracts" for Australian local industry to build components for the VLT. He came away believing it that it had been "a constructive meeting".

But a spokesman for McGauran said last week that "the offsets were few, and not adequate reason for $\mathbf{A} \$ 30$ million of support". He said astronomy in Australia already benefits from $\mathrm{A} \$ 32$ million in annual funding, and that the Australia Telescope had received $A \$ 11$ million for an upgrade in the Innovation Statement. "Astronomers cannot claim they have been hard done by," he says.

The shock decision came in a letter to Mould from McGauran last week. It prompted an immediate statement of "disappointment" by Sir Gustav Nossal, the president of the Academy of Science, only hours before hosting the academy's annual dinner at which McGauran was present. Although Mould said the letter did not rule out the possibility of membership of ESO being sought again "some years down the 
taken the first steps towards building new synchrotron radiation facilities. The French Centre National de la Recherche Scientifique (CNRS) and the Commissariat à l'Energie Atomique (CEA) were this week scheduled to approve a FF24-million (US\$4.7-million) detailed design phase for a 2.15-GeV machine, called Soleil.

This machine is intended to replace France's existing LURE facilities $(800 \mathrm{MeV}$ and $1.85 \mathrm{GeV}$ ) at Orsay, near Paris. The Swiss government last month also approved a SFr1.8-million (US\$1.46 million) study phase for a similar machine, the $2.1-\mathrm{GeV}$ Swiss Light Source (SLS).

All three countries are collaborating closely on plans to build third-generation synchrotron sources, in a bid to make savings by carrying out joint design work, and planning each machine to be as complementary as possible to the needs of user communities in all three countries, according to Catherine Cesarsky, the head of 'sciences of matter' at CEA.

One idea that has been floated would be to replace Diamond and Soleil with a shared SRS, built jointly by the United Kingdom and France. But Jacques Sevin, director of strategy and programmes at CNRS, argues that the demand for synchrotron radiation in each country is sufficient to justify building two machines, and points out that Diamond and Soleil would also be complementary, given that they would operate at different energy levels.

Newport argues that the task of building a single machine that could accommodate 6,000 users would reduce the potential for cost savings. But Cesarsky says that the proposal to build a single machine cannot be completely ruled out.

Declan Butler \& David Dickson

\section{ESO membership}

track", he said "the opportunity was now as contracts are soon to close out" and branded the decision as "abysmal".

Mould points out that a government survey showed astrophysics as Australia's "top science in international impact". He adds: "First-rate facilities have underpinned this performance. If Australian governments treat their best scientists in this way, what are the prospects for science as a whole?"

According to Mould, the astronomers are now "regrouping" for a further campaign. He says that he is disappointed that the minister would not allow negotiations to proceed, which Mould believes "would have led to a deal for phasing the payments to match the government's needs and constraints or an honourable disengagement".

Riccardo Giacconi, director general of the ESO, said that the Australian government's decision was to be "regretted". But, he is keen to keep lines of communication open between European and Australian scientists and engineers." Peter Pockley

\section{Argonne sees bright future from new photon source}

Washington. The long-term future of the Argonne National Laboratory near Chicago was effectively secured last week with the inauguration of the Advanced Photon Source (APS), providing US scientists with a new and immensely powerful X-ray source.

But many fear that the APS will prove to be the last large machine built according to past criteria of scientific need - and regional 'fairness' - and that raising funding for similar facilities in the future will prove to be considerably harder.

The \$1-billion, 7-GeV APS is comparable in specification to the European Synchrotron Radiation Facility (ESRF), which opened in France 18 months ago (see Nature 371, 469; 1994), and the Super Photon Ring now under construction in Japan.

In addition to the high electron-beam energies needed to produce 'hard' X-rays, this new generation of radiation synchrotrons is purpose-built to incorporate insertion devices, known as 'wigglers', which produce coherent X-ray beams of far greater brilliance than those from older synchrotrons.

About 2,000 scientists are expected to use the 35 beam lines that will collect X-rays from the APS synchrotron. Most of them will be materials scientists, chemists and structural biologists. But other disciplines will also make use of the penetrating $X$-rays to study molecular and crystal structures.

The arrival of the facility will "provide tremendous intellectual excitement" at Argonne, says Alan Schriesheim, the laboratory director, who is due to retire this summer after 12 years in charge.

The US Department of Energy has so far spent $\$ 800$ million to build the facility and to begin operation, and will budget around $\$ 70$ million a year for its operation. It has also attracted $\$ 160$ million from universities, other agencies and industries to equip the beam lines themselves, with about a quarter of that coming from the private sector.

Fifteen Collaborative Access Teams (CATs) have been set up to run the different beam lines. Most are consortia of industry, government laboratories and universities. But one - the Industrial Macromolecular Crystallography Association CAT - is a consortium of eleven pharmaceutical companies that will use its beam for drug design.

The APS is designed to complement the Advanced Light Source at the Lawrence Berkeley Laboratory in California, which opened in 1993 and supplies lower energy, 'soft' X-rays. In the view of some congressional staff, these machines ought to replace the existing radiation synchrotrons at the Brookhaven National Laboratory (BNL) on Long Island, New York, and at the Stanford

\section{Linear Accelerator Center in California.}

But the scientific reputation of these centres, together with their potential for industrial application - particularly in materials technology and drug design - has strengthened their case for funding. Even as APS comes on line, the National Synchrotron Light Source (NSLS) at BNL has had its operating budget increased this year to $\$ 26$ million, and is full to capacity, according to Michael Hart, its chairman.

Hart argues that most scientists do not need the extra brightness, the main asset of the APS. He points out that the NSLS is easy to upgrade, and that it "will remain competitive well into the next century".

Indeed, Burt Richter, the director of the Stanford Linear Accelerator Center (SLAC), points out that the opening of ESRF has not reduced demand for older facilities in Europe. The operating budget for the Stanford Synchrotron Research Laboratory has increased this year from $\$ 17$ million to $\$ 22$ million, keeping the machine on for 40 weeks instead of 30: Richter expects

IMAGE
UNAVAILABLE
FOR COPYRIGHT
REASONS

Wigglers at work: light simulates particles.

users to grow by 15 per cent this year.

David Moncton, associate director for APS at Argonne, says that his enthusiasm for the new machine is tinged by sadness at the thought that the US Department of Energy may never build a machine like APS again. But Jim Decker, deputy director of the Office of Energy Research at DoE, says: "I don't believe that for a minute." He adds: "People look at the budget climate and say it isn't possible to build anything new. That doesn't mean that in a couple of years the budget climate isn't going to change."

Clearly, however, the APS is the product of a different era. As one senior official of the time puts it: "When the SSC [the Superconducting Super Collider in Texas, since cancelled] got started, every laboratory was to get a toy for itself". Colin Macilwain 